\title{
Assessment of Some Biomarkers under Submergence Stress in Some Rice Cultivars Varying in Responses
}

\author{
Sidhartha Banerjee ${ }^{1^{*}}$, Narottam Dey ${ }^{2}$, Malay Kumar Adak ${ }^{*} \#$ \\ ${ }^{1}$ Plant Physiology and Molecular Biology Research Unit, Department of Botany, University of Kalyani, Kalyani, \\ India \\ ${ }^{2}$ Department of Biotechnology, Visvabharati, Santiniketan, India \\ Email: ${ }^{\#}$ mkadak09@gmail.com
}

Received 5 December 2014; revised 19 December 2014; accepted 28 December 2014

Copyright @ 2015 by authors and Scientific Research Publishing Inc.

This work is licensed under the Creative Commons Attribution International License (CC BY). http://creativecommons.org/licenses/by/4.0/

\section{(c) (7) Open Access}

\begin{abstract}
Three rice varieties, significantly differed in their ability, when subjected to submergence have been studied in relation to physiological attributes. On account of oxidative stress, MDA content and carbonyl content were measured. The MDA content was maximally decreased in FR13A and minimally decreased in Swarna irrespective of shoots and roots. A higher increase in carbonyl content was found in Swarna followed by FR13A and Swarna Sub1A in both shoots and roots. The activity of antioxidant moieties like total phenolics content and flavonoid content were more increased under submergence than that in air except for Swarna. FR13A showed maximum increase in Phenolics and flavonoid content in both shoots and roots when subjected to submergence. A sharp increase in guaiacol peroxidase and glutathione reductase characterized the plants' response to sub-mergence irrespective of varieties. The expression of Guaiacol peroxidase was increased in FR13A followed by Swarna Sub1A and Swarna. Glutathione reductase was measured in terms of oxidation of NADP(H) and both FR13A and Swarna Sub1A recorded maximum oxidation than Swarna under submergence. With regards to isozymic variation plants were differed to the intensities of poly-peptide, however not in numbers and may be suggestive for concomitant gene expression to sub-mergence. The analysis clarification for possible biomarkers with regards to cellular responses of rice plants under submergence has been anticipated.
\end{abstract}

\section{Keywords}

Biomarkers, Oxidative Stress, Submergence, Rice, Antioxidant

\footnotetext{
${ }^{*}$ S. Banerjee and M. K. Adak have contributed equally.

"Corresponding author.
}

How to cite this paper: Banerjee, S., Dey, N. and Adak, M.K. (2015) Assessment of Some Biomarkers under Submergence Stress in Some Rice Cultivars Varying in Responses. American Journal of Plant Sciences, 6, 84-94. 


\section{Introduction}

Rice, the semi aquatic plant is the major staple food as accepted globally. In due course of agricultural and industrial thrust, the production of rice has reached a satisfactory level still, yet to achieve the ever demanding worldwide needs. Moreover, this becomes a constraint with the different environmental fluctuations like water deficits or excess, salinity, heavy metal imposition in soil, temperature extremities, oxidative burst etc. [1]. Out of those the abundance or excess water in rice fallows very often pose a serious problem which keeps the sustainability of rice in a threatened condition, particularly, at seedling stages. Stagnation of water in different depth and duration is classically referred as water logging and submergence stress with reference to partial or complete inundation of rice seedlings [2] [3]. The later is sensed as submergence stress globally with a coverage of $16 \%$ ( $\sim 22 \mathrm{~m} \mathrm{ha}$ ) of rice cultivable area [4]. Submergence stress is more obviously detrimental when rice plants experience some sort of oxidative exposure. This is more prevalent for rice seedlings being completely inundated under water and thereafter a sudden recede of water level. In rice agricultural practices, this is more common when submergence is more wide spread in the form of flash flood [2] [5] [6]. In this condition the anoxic or hypoxic stress tissues are suddenly exposed to oxygen tension when the water level recedes either partially or fully. This gives the plants a drive for typical environmental signal in respect to changes in oxidation status. This over oxidised status is referred to as oxidative stress to plants and thereby plants become much prone or vulnerable to oxidative damages of biomolecules in different degrees. As a result of extreme stress conditions, a number of reactive oxygen species (ROS) so accumulated leads to engage in many degenerative processes [7]. The breakage of the DNA with ROS exposure results in impaired protein synthesis and thus plants fail to evoke its tolerance under such conditions [8]. For oxidative damages most of the reactions are irreversible in nature and thus ensures a permanent oxidation of important amino acid residues of many functional proteins for which rice varieties are evoked with special cellular events to induce the antioxidation pathway [9]. This is also associated with the induction of different genes for their up and down regulation, photophosphorylation and dephosphorylation system in signalling of many cellular pathways. Collectively all the reactions which are predominantly and eventually focussed on antioxidation cascades are most concerned to submergence stress. Therefore, typical metabolic reactions are required to set as biomarkers which can highlight the real oxidative stress so developed under such condition. In rice, particularly the seedling stages are more prone to complete submergence vis-a-vis to oxidative damages and are required to be illustrated with suitable cellular responses behaving as biomarkers. So, a close analysis into biomarkers under oxidative stress responses could be successful hints on plants behaviour towards ROS and thereby their earlier detection is made possible. More so, the oxidative stress biomarker is based on some up/down regulation of suitable candidate genes for their selection in breeding programmes. In the present experiment, thus, three rice genotypes varying in submergence tolerance have been dealt with some cellular responses under oxidative stress and thus are hypothesised for possible biomarkers in rice as discussed.

\section{Materials and Method}

In order to fulfill the aforesaid objectives, an experiment was conducted in the laboratory of Plant Physiology and Plant molecular Biology Research Unit, Department of Botany, University of Kalyani, Kalyani-741235, West Bengal, India. Seeds of three rice varieties (namely Swarna, Swarna Sub1A and FR13A) were collected from Rice Research Institute, Chinsurah, West Bengal, India. Out of these three varieties, Swarna is submergence sensitive; FR13A is a naturally occurring submergence tolerant variety whereas Swarna Sub1A has been made submergence tolerant by the introgression of Sub1 allele from FR13A. Thus, these three varieties may prove their efficacies in distinguishing different physiological parameters under inundation. The seeds were first soaked in $0.1 \%$ mercuric chloride for 15 minutes, followed by rinsing them in distilled water thrice. The seeds were then kept for germination on plastic trays at $37^{\circ} \mathrm{C}$ for 5 days. Germinated seedlings of uniform appearance were selected and transplanted to earthen pots containing $5 \mathrm{~kg}$ of alluvial soil (containing 58.9, 4.5 and 64.7 $\mathrm{mg} \cdot \mathrm{kg}^{-1}$ of $\mathrm{N}, \mathrm{P}$ and $\mathrm{K}$ respectively in the form of urea, single super phosphate and muriate of potash respectively) with 7 seedlings per pot. Plants were grown in a green house and subjected to natural conditions of temperature $\left(34^{\circ} \mathrm{C}-37^{\circ} \mathrm{C}\right)$, photoperiod $(13 / 11$ hour light/dark) with $70 \%-75 \%$ relative humidity. The entire work was carried out during the summer season (April-June 2013). Fourteen-days-old seedlings were submerged for 7 days in a cemented tank under $90 \mathrm{~cm}$ depth of water from the floor in order to submerge the plants completely [10]. Inundation of the seedlings at this stage beyond 7 days may affect their lives. After completion of 7 days of submergence, plants were taken out of the water, separated into roots and shoots and the estimation of different 
metabolites were done according to standard referred protocols.

\subsection{Estimation of MDA Content}

The lipid peroxidation was measured in terms of malondialdehyde content (MDA). $1 \mathrm{~g}$ of fresh plant samples from control and each treatment were ground in liquid nitrogen and extracted with $0.1 \%$ trichloroacetic acid (TCA). Homogenate was centrifuged at $10,000 \times \mathrm{g}$ for $10 \mathrm{~min}$ at $4^{\circ} \mathrm{C} .1 \mathrm{ml}$ supernatant was collected and mixed with $0.5 \%$ thiobarbituric acid (TBA) in $20 \%(\mathrm{w} / \mathrm{v})$ trichloroacetic acid (TCA) and incubated at $95^{\circ} \mathrm{C}$ for $30 \mathrm{~min}$. On completion, it was immediately placed in ice for $30 \mathrm{~min}$ followed by centrifugation at $12,500 \times \mathrm{g}$ for $10 \mathrm{~min}$. The absorbance of the supernatant was read at $532 \mathrm{~nm}$ and $600 \mathrm{~nm}$ and expressed as $\mu \mathrm{M} \cdot \mathrm{g}^{-1}$ fresh weight (FW) and MDA content was derived according to [11].

\subsection{Estimation of Carbonyl Content}

For the protein oxidation, the carbonyl content of fresh plant sample was determined in a reaction with dinitrophenyl hydragene (DNPH) reagent according to [12]. $1 \mathrm{~g}$ sample (whole plant) was thoroughly crushed in liquid nitrogen and extracted with $6 \%(\mathrm{w} / \mathrm{v})$ sodium lauryl sulphate (SDS) followed by incubation at $37^{\circ} \mathrm{C}$ for $30 \mathrm{~min}$. Then, to this, $10 \mathrm{mM}$ DNPH in $1.5 \mathrm{mM}$ TCA was added and further gently agitated at every 10 min interval for an $\mathrm{h}$. The protein was precipitated by TCA (w/v) on ice and protein pellet was recovered by centrifugation at $15,000 \times$ g followed by re-extracted with $20 \%(\mathrm{w} / \mathrm{v})$ TCA. The pellet was suspended completely in $0.2 \mathrm{M}$ sodium phosphate buffer ( $\mathrm{pH} \mathrm{7)}$ and the absorbance was recorded at $360 \mathrm{~nm}$. Finally, the protein-carbonyl complex content was calculated using the molar extinction coefficient $\left(530 \mathrm{M}^{-1} \cdot \mathrm{cm}^{-1}\right)$ of DNPH and expressed in $\mu \mathrm{M} \cdot \mathrm{g}^{-1}$ fresh weight (FW) protein. The protein content of the sample was determined with Bradford reagent [13].

\subsection{Estimation of Total Phenolics}

$1 \mathrm{~g}$ of tissue (whole plant) was crushed in liquid nitrogen and homogenized in $80 \%$ hot ethanol and centrifuged at $10,000 \times \mathrm{g}$ for $20 \mathrm{~min}$ at $4^{\circ} \mathrm{C}$. The supernatant was kept in a water bath to evaporate ethanol and dried it. Then the residue was dissolved in a $5 \mathrm{ml}$ of double distilled water. An aliquot of $0.5 \mathrm{ml}$ was treated with Folin-Ciocalteu reagent. Then after 2 min, $20 \%$ sodium carbonate $\left(\mathrm{Na}_{2} \mathrm{CO}_{3}\right)$ was added and the content was mixed thoroughly. The mixture was incubated in a boiling water bath for $1 \mathrm{~min}$. After cooling, the intensity of color was measured at $650 \mathrm{~nm}$ and the phenol content was derived with gallic acid as standard according to [14] and ex-

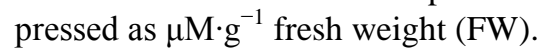

\subsection{Estimation of Flavonoid}

The major antioxidant, flavonoid was assayed from control and treated plants. $1 \mathrm{~g}$ of the fresh sample was extracted in $80 \%$ aqueous ethanol followed by centrifugation at $10000 \times \mathrm{g}$ at room temperature for $20 \mathrm{~min}$. The supernatant was saved; $1 \mathrm{ml}$ of supernatant was diluted with $4 \mathrm{ml}$ of de-ionized water and added with a reaction mixture containing $0.3 \mathrm{ml}$ of $5 \%$ sodium nitrite $\left(\mathrm{NaNO}_{2}\right)$ and $0.3 \mathrm{ml}$ of $10 \%$ aluminium chloride $\left(\mathrm{AlCl}_{3}\right)$. Finally after 6 min, the reaction mixture was diluted with $2 \mathrm{ml}$ of $1 \mathrm{M} \mathrm{NaOH}$ then, total volume was made up to 10 $\mathrm{ml}$ by double distilled water. The absorption was recorded at $510 \mathrm{~nm}$. The total flavonoid was determined with a standard of quercetein and expressed as $\mu \mathrm{M} \cdot \mathrm{g}^{-1}$ fresh weight (FW) [15].

\subsection{Assay of Guaiacol Peroxidase}

It was assayed spectrophotometrically using O-dianisidine as electron donor and hydrogen peroxide (H2O2) as substrate according to [16]. After crushing the sample with liquid nitrogen, it was homogenized with $0.1 \mathrm{M}$ phosphate buffer ( $\mathrm{pH}$ 6.5). The homogenate was centrifuged at $12,000 \times \mathrm{g}$ for $10 \mathrm{~min}$ and then supernatant was saved for assay. Enzyme extract containing equal amount of protein $(50 \mu \mathrm{g})$ was added in an assay mixture, containing $0.1 \mathrm{M}$ phosphate buffer ( $\mathrm{pH}$ 6.5), $1.5 \mathrm{mM}$ freshly prepared O-dianisidine, $0.2 \mathrm{M} \mathrm{H}_{2} \mathrm{O}_{2}$. The change of absorbance was monitored at $430 \mathrm{~nm}$ and the enzyme activity was determined according to [17] using an extinction coefficient of O-dianisidine $\left(26.2 \mathrm{mM}^{-1} \cdot \mathrm{cm}^{-1}\right)$. One unit (U) of enzyme is defined, as the time required for changing the absorbance by 0.1 per unit microgram of protein. For in gel studies of isozymes of GPX, the equal 
amount of protein was run in a non-denaturing $10 \%$ polyacrylamide gel at $10 \mathrm{~V} / \mathrm{lane}$ under cold condition [18] [19]. The detection of specific band of polypeptide was resolved in an incubation mixture composed of $50 \mathrm{mM}$ Potassium phosphate buffer ( $\mathrm{pH}$ 6.5), $0.5 \mathrm{mM}$ O-dianisidine and $0.5 \% \mathrm{H}_{2} \mathrm{O}_{2}$.

\subsection{Assay of Glutathione Reductase}

Activity was assayed according to [20]. After grinding the sample in liquid nitrogen and homogenizing ho-

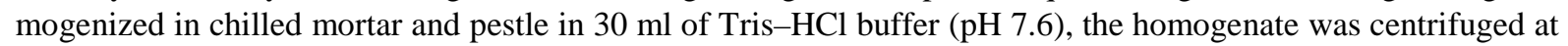
$22,000 \times \mathrm{g}$ for $30 \mathrm{~min}$ at $4^{\circ} \mathrm{C}$. The assay mixture prepared by $50 \mathrm{mM}$ Tris- $\mathrm{HCl}$ buffer (pH 7.6), $0.5 \mathrm{mM}$ DTT, 3 $\mathrm{mM}$ magnesium chloride $\left(\mathrm{MgCl}_{2}\right), 0.15 \mathrm{mM} \mathrm{NADPH}, 1 \mathrm{mM}$ oxidized glutathione (GSSG) then incubated at $37^{\circ} \mathrm{C}$ for $15 \mathrm{~min}$ and followed by immediate addition of $50 \mu \mathrm{g}$ of enzyme protein. The activity was recorded from oxidation of NAD(P)H with its extinction coefficient $6.22 \mathrm{mM}^{-1} \cdot \mathrm{cm}^{-1}$. One unit (U) of enzyme was regarded as $\mu \mathrm{M}$ NADPH oxidized $\mathrm{min}^{-1} \cdot \mathrm{g}^{-1}$ protein. The isoforms of GR was detected by electrophoresis of protein $\left(50 \mu \mathrm{g} \cdot \mathrm{lane}^{-1}\right)$ in a non-denaturing polyacrylamide (10\%) native gel and run at 60 and $100 \mathrm{~V}$ in stacking and resolving gel respectively under cold condition. The bands were developed on the gel after incubating it in a mixture containing $0.5 \mathrm{mM}$ NAD(P)H, $3.4 \mathrm{mM}$ GSSG, $0.5 \mathrm{mM}$ EDTA, $25 \mathrm{mM}$ Tris-HCl (pH 7.6), dichlorophenol indophenol (DCPIP), 3-(4,5-dimethyl-2 thiazolyl 2,5 diphenyl-tetrazolium bromine) (MTT) under dark condition for $10 \mathrm{~min}$ [21].

\section{Results}

In general, lipid peroxidation follows the linear correlation with ROS generated in oxidative stress and other factors inducing the same. Still, the varieties in the present experiment recorded minimised values of MDA with respect to control. Interesting to note that SUB1A allele possessing by FR13A has maximally curtailed the MDA content by 24.1 percent whereas the variety Swarna has minimally curtailed the MDA content by 22.3 percent in shoots. The variety Swarna Sub1A has recorded an intermediatory decrease of MDA content by 23.7 percent under submergence in shoots when compared to other two varieties (Figure 1(a)). In roots also, the trend was similar to shoots with 52.6 percent decrease in FR13A and 45 percent decrease in Swarna with intermediatory decrease in Swarna Sub1A with 50.1 percent (Figure 1(b)). Protein oxidation refers another key to estimate oxidative damages and thereby loss of protein out of abiotic stresses. The estimation of carbonyl content in protein oxidation therefore, bears the direct relationship of ROS induced protein denaturation during submergence also. Thus, submergence inducing the oxidative stress in the present experiment recorded a higher increase in carbonyl content in the shoots of Swarna (2.25 fold) with respect to other varieties FR13A (2.08 fold) and Swarna Sub1A (1.70 fold) (Figure 2(a)). For roots, a similar trend of observation was recorded with higher increase in carbonyl content in submergence sensitive Swarna (2.42 fold) with respect to other tolerant varieties FR13A (2.03 fold) and Swarna Sub1A (1.65 fold) (Figure 2(b)). Total phenolics constitute the pool of all non enzymatic constituents which come under various molecular constituents. Phenolic accumulation had shown some interesting pattern being over accumulated under submergence except in Swarna. The other two varieties like FR13A and Swarna Sub1A had been up regulated by 1.59 fold and 1.54 fold in total phenolics content in shoots. However, for Swarna it has been reduced by 65.5 percent over control (Figure 3(a)). Almost a similar trend of accumulation was recorded in case of root where the changes in phenolics content was maximum in FR13A (1.70 fold) followed by Swarna Sub1A (1.63 fold). However, there was a decrease in phenolic content in Swarna by 61.5 percent under submergence as compared to normal (Figure 3(b)). Flavonoid, a group of phenolics, is regarded as the most abundant antioxidant irrespective of plant species under oxidative stress. In this experiment, plants recorded a linear up regulation of flavonoid content regardless of varieties (Figure 4). The highest increase in flavonoid content was observed in the shoots of FR13A (1.28 fold) followed by Swarna Sub1A (1.25 fold) and Swarna (1.14 fold) (Figure 4(a)). A similar trend in case of roots was observed with higher levels of flavonoid in FR13A (1.41 fold) followed by Swarna Sub1A (1.38) fold and Swarna (1.14 fold) (Figure 4(b)). The activity of GPX, the most abundant isoforms in sub-cellular fractions in tissues with guaiacol as electron donors happened to be more crucial as bio marker in the present experiment. Interestingly, submergence had more impacted for GPX induction in varieties Swarna Sub1A and FR13A than the sensitive Swarna. Thus, FR13A had the conformity with earlier literature by scoring the maximum peroxidase activity with 1.86 fold under induction of submergence when compared to control (Figure 5(a)). The variety Swarna Sub1A had also the up regulated values for GPX activity with 1.25 fold over the control, where as the variety Swarna re- 


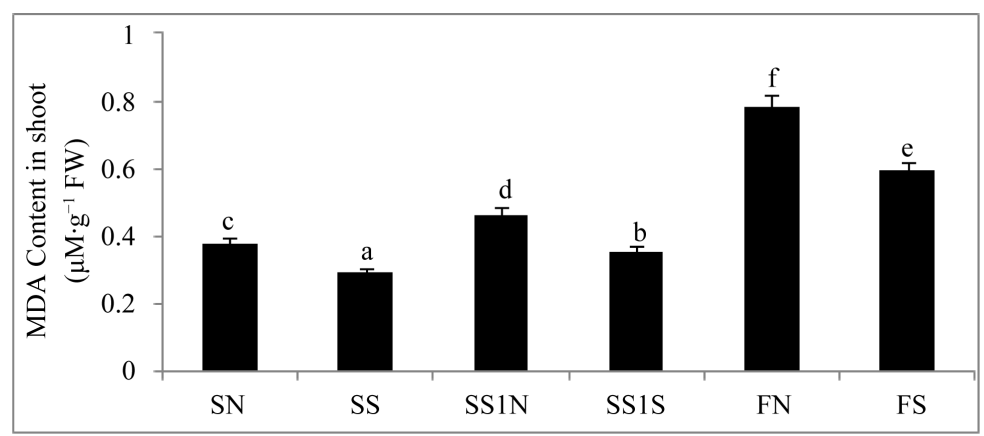

(a)

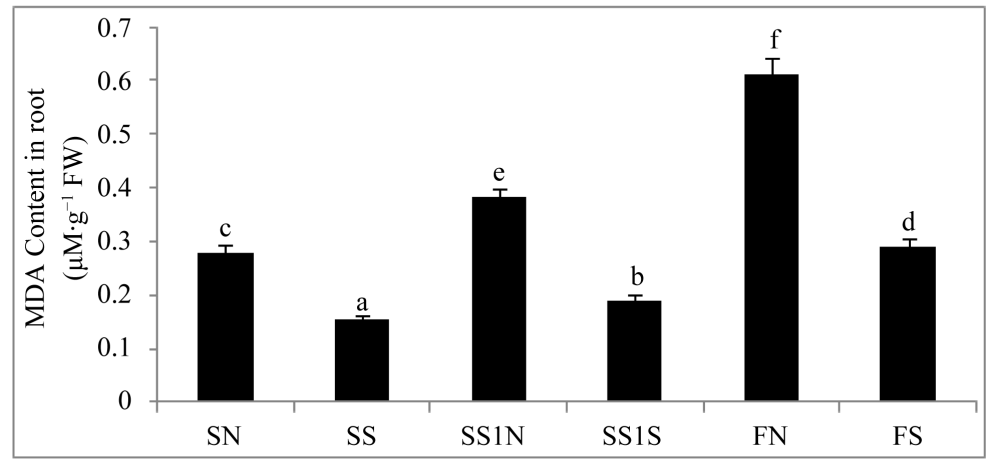

(b)

Figure 1. Changes in Lipid Peroxidation (a) shoot and (b) root under 7 days of complete submergence of rice genotypes. The data presented herein with the mean \pm S.E. of three replicates $(n=3)$. The different letters on each bar denotes the significant differences $(\mathrm{p} \leq 0.05)$. SN-Swarna under normal, SSSwarna under submergence, SS1N-Swarna Sub1A under normal, SS1SSwarna Sub1 under submergence, FN-FR13A under normal and FS-FR13A under submergence.

mained hardly any significant variation of GPX activity between normal and submergence. Submergence has tended a significant upregulation of antioxidation pathway with ref to retrieval of reduced glutathione. It is evident from the Figure 5(b) that the activity of GR was upregulated irrespective of varieties like Swarna, Swarna Sub1A and FR13A. However, the activity increased almost the cases by 1.44 fold, 1.25 fold and 1.25 fold over the control still it is noted that FR13A and Swarna Sub1A had not significantly being varied in enzyme activity as compared to normal.

\section{Discussion}

The preliminary strategies for plants to encounter the oxidative stress involve the exercise of antioxidative pathways. Still, the common antioxidants have occasionally come in context to all kinds of stresses, even under submergence for rice also. However, analysis of total transcriptional organizing mechanism advocates not only for a single gene but also the cascades of different gene action under submergence [1]. Both up and down regulation of the metabolic pathways (as mentioned in the result portion) are concerned in response to submergence of the plants. This is also experienced for rice varieties in the present experiment.

Loss of protein by peroxidation reaction seems to be preliminary for plant's response to oxidative stress. Protein oxidation is referred as the development of carbamylated derivatives through amino acid oxidation by ROS, mostly with free $\mathrm{OH}$. [22]. Under submergence the oxidation of protein occurs earlier than lipid peroxidation and this facilitates the degenerative processes for hypoxia/ anoxia stressed plants [23]. Higher carbonyl content in the shoots and roots of submergence sensitive variety may suggest higher proteolytic activity in them due to stress with respect to the submergence tolerant varieties. Thus, the varieties FR13A as well as Swarna Sub1A had comparative lesser damages due to protein and lipid peroxidation than Swarna. Importantly, FR13A possess 


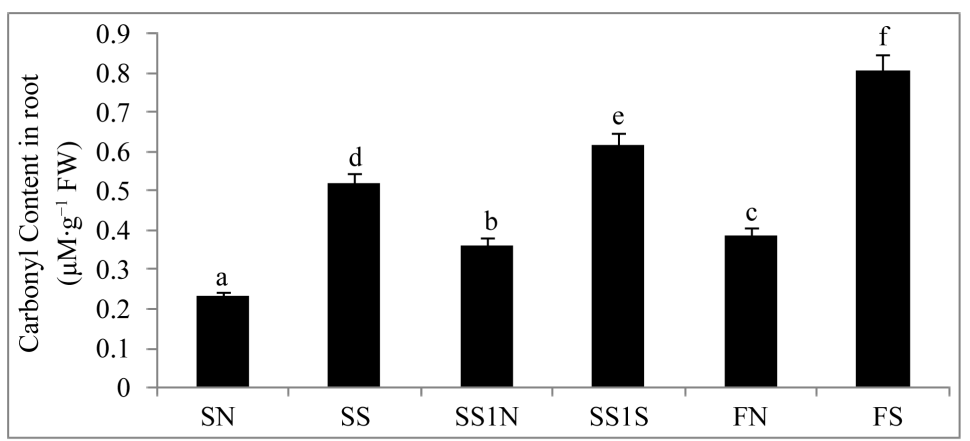

(a)

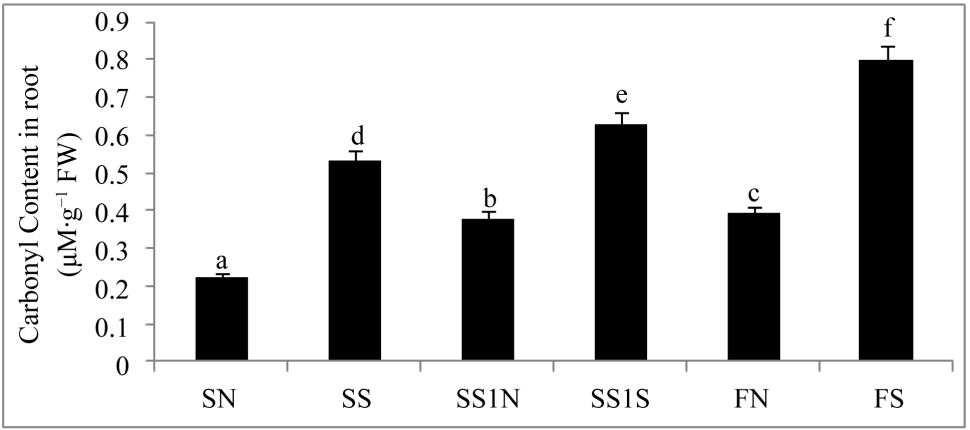

(b)

Figure 2. Changes in Protein oxidation (a) shoot and (b) root under 7 days of complete submergence of rice genotypes. The data presented herein with the mean \pm S.E. of three replicates $(n=3)$. The different letters on each bar denotes the significant differences $(\mathrm{p} \leq 0.05)$. SN-Swarna under normal, SSSwarna under submergence, SS1N-Swarna Sub1A under normal, SS1SSwarna Sub1 under submergence, FN-FR13A under normal and FS-FR13A under submergence.

the QTL for SUB1A allele that actually restricts the sugar utilizing capability during submergence thereby preventing cellular elongation [24] [25]. This gives the clue for enhanced catabolism of storage carbohydrate through aerobic or/and anaerobic pathways. On the other hand, the Sub1 allele in FR13A also helps in the expression of genes that are required for the detoxification of ROS. The over-accumulation of ethylene in the tissues, particularly, in anoxic/hypoxic condition circumvents the accessibility of $\mathrm{NAD}(\mathrm{P}) \mathrm{H}$ oxidase activity, the key enzyme for ROS generation [26]. Therefore, the Sub1 allele itself is contributory in ethylene suppression has every possibility to down regulate the ROS generation and its concomitant impact. This is more with when electrons divert its path to molecular oxygen $\left(\mathrm{O}_{2}\right)$ instead to $\mathrm{O}_{2}^{-}$, under various abiotic stresses including submergence. More so, anaerobic condition for rice culture very often establishes the susceptibility for tissues to be hyper-acted with lipoxigenase activity and that sets another path for generation of ROS [7]. Submergence becomes equally important to raise the condition for photorespiration, particularly, when plants are exposed to direct aerobic condition with recede of water level. However, collectively the higher content of carbonyl and lipid peroxide derivatives in senescent leaves of submerged rice varieties may be served as suitable bio markers for oxidative stress. Plants response to abiotic stresses particularly in the form of ROS perception and its concomitant sensitivity. Submergence is commonly attributed to establish a hypoxic stress earlier than it is experienced for oxidative stress. Since the stomata are not closed under submergence like that of water stress, the plants cannot perceive the stress out of more oxygen exposure. But when plants are exposed out from submergence particularly in reaerated condition, the high oxygen pressure is built inside the tissue through open stomata and chances of ROS development becomes high. Similar findings have also been reported [27]. Still in few cases plants are shown with the contradiction of over expression of ROS even under submergence. Phenolics with its diverse nature of molecular configurations have ranked it the most efficient in quenching of ROS energy. Under submergence the plants have significantly up regulated the accumulation of flavonoid content regardless of va- 


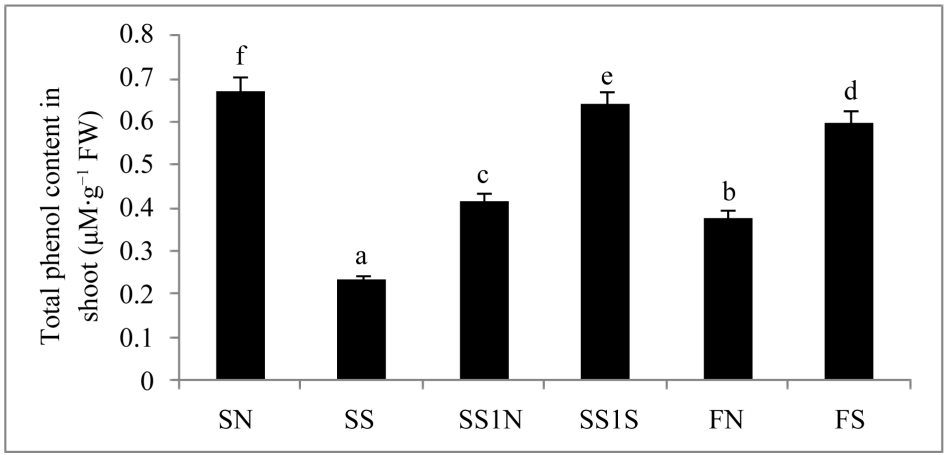

(a)

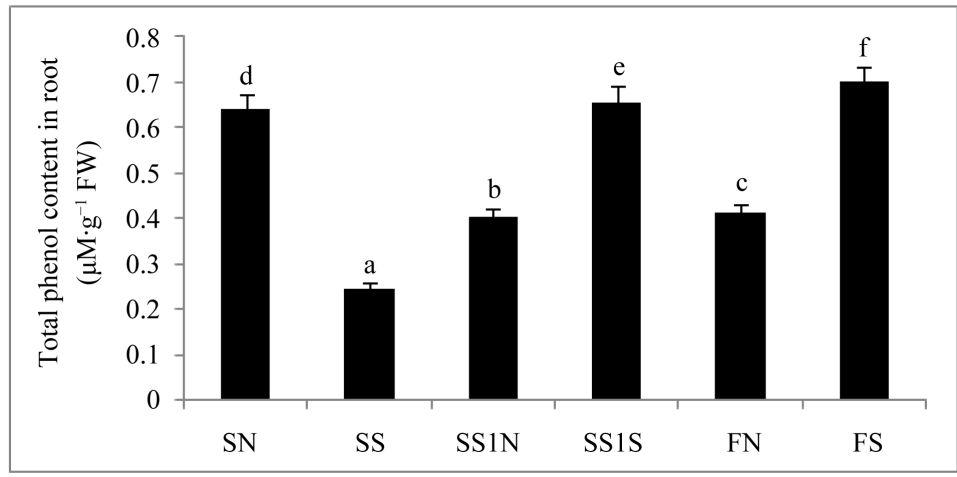

(b)

Figure 3. Changes in Total phenol content (a) shoot and (b) root under 7 days of complete submergence of rice genotypes. The data presented herein with the mean \pm S.E of three replicates $(n=3)$. The different letters on each bar denotes the significant differences $(\mathrm{p} \leq 0.05)$. SN-Swarna under normal, SSSwarna under submergence, SS1N-Swarna Sub1A under normal, SS1SSwarna Sub1 under submergence, FN-FR13A under normal and FS-FR13A under submergence.

rieties [28]. For the varietal performances it was FR13A followed by Swarna Sub1A which had more phenolics accumulation than Swarna. Flavonoid biosynthesis has been well documented in other crops under various inputs of environmental extremities; however, for submergence it was less explored. The ethylene mediated ROS generation in submerged tissues might be a clue for more phenolics accumulation in the tissues. The one mode of submergence response mediated by ethylene could initially be triggered by ABA. ABA besides antagonizing both epidermal cell death and adventitious root elongation (as promoted by ethylene), may also induce gene expression in phenyl propanoid pathways [6]. The anoxic or hypoxic tissues could reduce the endogenous level of ABA in deep water rice as well as low land indica varieties [3]. Accumulation of excess ethylene precursor or ethylene itself during submergence may also relieve the ABA in rice leaf sheath. Therefore, any of the key regulatory pathways for phenyl propanoid biosynthesis undergoes free from ABA interference. Thus, SUB1A along with modulation of carbohydrate metabolism may also be illustrated with phenolic conversion through intricacies with ethylene suppression. Rice genotypes possessing Sub1A allele are also benefitted from phenolics, particularly, for the ability to amend the peroxidation properties. This is done by decrease in fluidity of lipids in the membrane. Thereby, the diffusion of ROS is hindered into the sub cellular membrane and lowers the lipid peroxidation.

In regards to antioxidation strategies for submerged plants for ROS homeostasis, a number of antioxidative enzymes are required. A wide array of antioxidative enzymes in concerted action of various phenolic residues as electron donors is important in this aspect. The SUB1A locus in submergence tolerant cultivars are actually displayed with ethylene response factors (ERFs) that could suppress the ethylene production as well as its sensitivity to the tissues concerned [29]. FR13A could be cited as the most suitable example where a significant down 


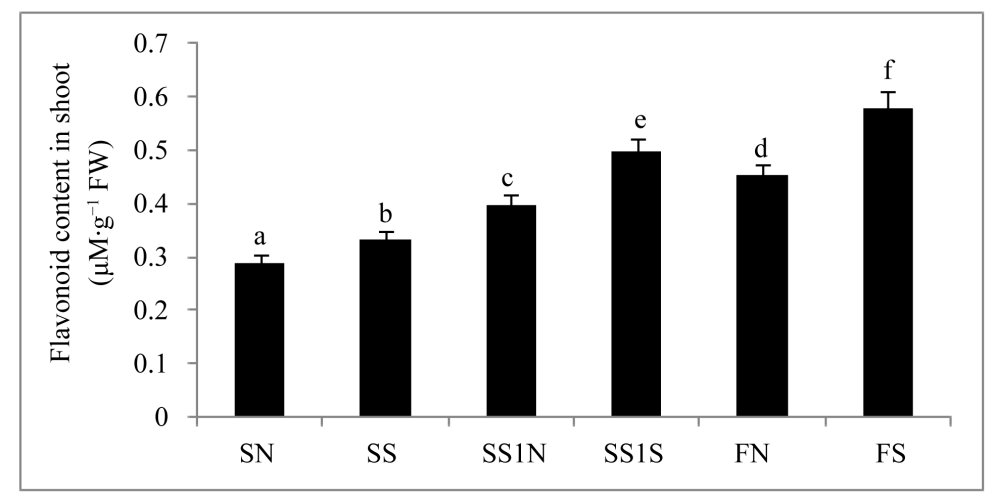

(a)

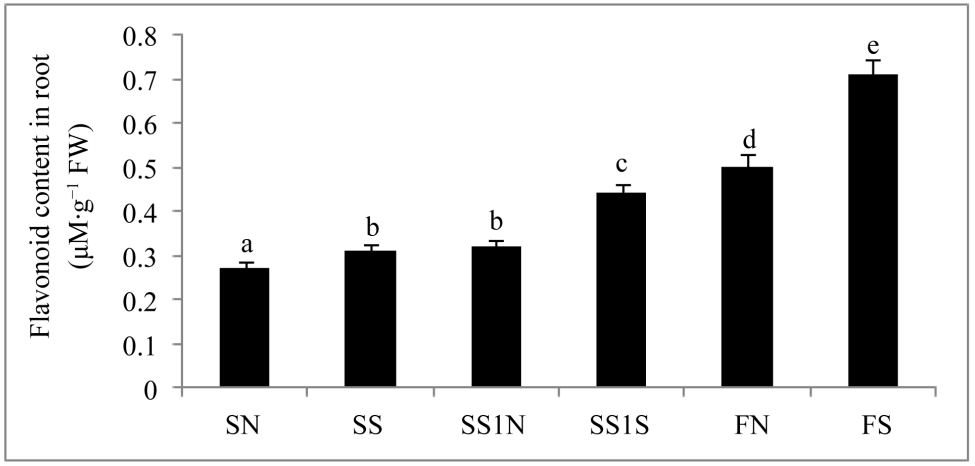

(b)

Figure 4. Changes in Flavonoid content (a) shoot and (b) root under 7 days of complete submergence of rice genotypes. The data presented herein with the mean \pm S.E. of three replicates $(n=3)$. The different letters on each bar denotes the significant differences $(\mathrm{p} \leq 0.05$ ). SN-Swarna under normal, SSSwarna under submergence, SS1N-Swarna Sub1A under normal, SS1SSwarna Sub1 under submergence, FN-FR13A under normal and FS-FR13A under submergence.

regulation of ethylene concomitantly inhibits the tissue elongation of internodes and leaf sheath. The lesser sensitivity could also be triggering for up regulation of various genes like GPX, GR which has characterized FR13A and Swarna Sub1A much ahead of Swarna. Regardless of varieties a significant up regulation of both GPX and GR activity under stress essentially established the detoxification of ROS [30]. Moreover, the activity staining in gel for GPX (Figure 6) and GR also holds true for occurrence of polymorphisms and their variations within the tissue specific. Illustration with GPX isoforms with that of guaiacol as phenolic electron donor could also be able to generate free radicals [31]. A significant variation was recorded under anoxic and hypoxic condition in terms of ROS scavenging activities in plants. In general, peroxidase activity is up regulated under ROS mediated toxication as found in crops like rice, wheat, Iris etc. [25]. However, this was not true for barley and maize which recorded substantial accumulation of super oxide with curtailing of redox through glutathione accumulation in its reduced form [25]. Therefore, GR activity could reflect otherwise the plant's ability to compensate redox potential which undergoes depleted under submergence. Along the same line with GPX activity, the tolerant cultivar FR13A had been promising to up regulate the GR activity. The isozymic profile of GR, though not varied with band numbers but with intensities of the polypeptides.

\section{Conclusion}

Conclusively, it is well perceived that regulation of ROS activity under submergence relies on control of its generation as well as lysis. It is also true that tolerant species has the intrinsic ability to quench the excess energy of ROS by over-expressing the potentials of various antioxidant moieties. Still, it is unquestionable that ROS activity and its amelioration are regulated at different levels varying according to species. However, with the illus- 


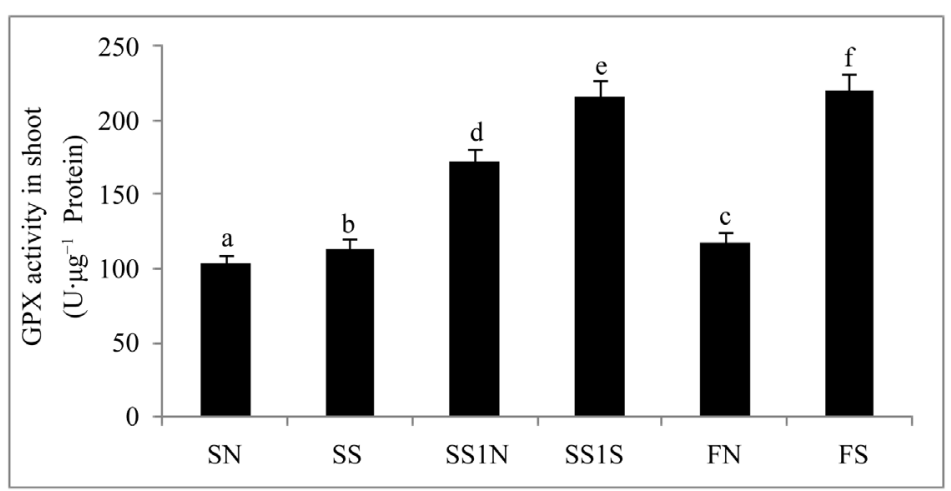

(a)

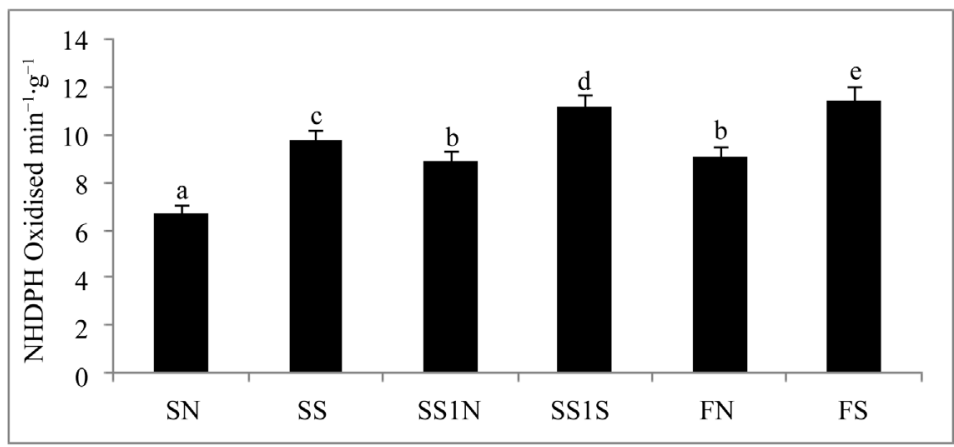

(b)

Figure 5. Changes in (a) GPX activity shoot and (b) GR activity shoot under 7 days of complete submergence of rice genotypes. The data presented herein with the mean \pm S.E. of three replicates $(n=3)$. The different letters on each bar denotes the significant differences $(\mathrm{p} \leq 0.05)$. SN-Swarna under normal, SS-Swarna under submergence, SS1N-Swarna Sub1A under normal, SS1SSwarna Sub1 under submergence, FN-FR13A under normal and FS-FR13A under submergence.

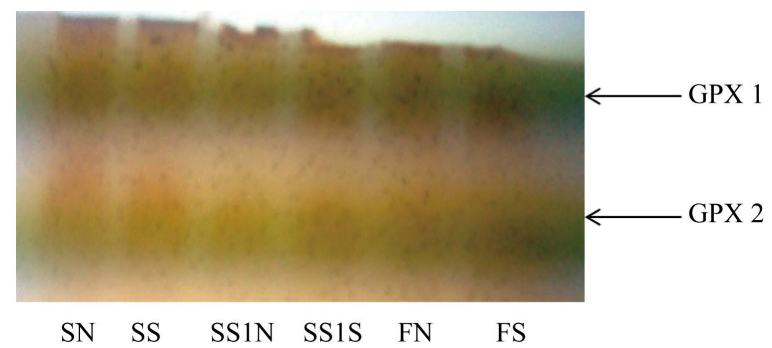

Figure 6. Study of GPX isoforms through activity staining under 7 days of complete submergence of rice genotypes. SNSwarna under normal, SS-Swarna under submergence, SS1NSwarna Sub1A under normal, SS1S-Swarna Sub1 under submergence, FN-FR13A under normal and FS-FR13A under submergence.

tration of rice, the submergence tolerance is also equally attributed by a fine tuned regulatory system of antioxidation integrally conjoined with SUB1A activity. More so, with reference to FR13A and its introgressed cultivar Swarna Sub1A have the similar responses with ethylene mediated signalling of ROS antioxidation. This was more emphasized from the facts of ethylene mediated tissue lysis, development of aerenchyma formation accompanied with ROS (like $\mathrm{H}_{2} \mathrm{O}_{2}$ ) generation. The later elicits the pathways of antioxidation of many genes contiguous with SUB1A related carbohydrate metabolism. This is more prudent from the present experiment com- 
paring with oxidative damages and other responses between submergence/flood resistant and sensitive varieties. Therefore, submergence stress in rice and its reactions might employ the oxidative responses in plants as bioindicators. This could also be extrapolated to identify other unifying in sights for cellular responses adhered to oxidative stress under submergence for characterizing flood resistant genotypes.

\section{Acknowledgements}

Authors are thankful to Dr. B. Adhikary, Principal Scientist, Rice Research Institute, Chinsurah, West Bengal for providing the seed materials. This work was financially supported by DST-PURSE programme, Department of Science and Technology, New Delhi.

\section{References}

[1] Fukao, T., Yeung, E. and Bailey-Serres, J. (2011) The Submergence Tolerance Regulator SUB1A Mediates Crosstalk between Submergence and Drought Tolerance in Rice. The Plant Cell, 23, 412-427.

http://dx.doi.org/10.1105/tpc.110.080325

[2] Catling, D. (1992) Rice in Deep Water. MacMillan Press, London.

[3] Hattori. Y., Nagai. K. and Ashikari, M. (2011) Rice Growth Adapting to Deepwater. Current Opinion in Plant Biology, 14, 100-105. http://dx.doi.org/10.1016/j.pbi.2010.09.008

[4] Ray, B.P., Sarker, S.K. and Sarker, M. (2013) Genotype Selection and Selection Criteria of Submergence Tolerant Rice (Oryza sativa L.). The Journal of Biological Chemistry, 2, 409-420.

[5] Bailey-Serres, J., Fukao, T., Ronald, P., Ismail, A., Heuer, S. and Mackill, D. (2010) Submergence Tolerant Rice: SUB1A's Journey from Landrace to Modern Cultivar. Rice, 3, 138-147. http://dx.doi.org/10.1007/s12284-010-9048-5

[6] Jackson, M.B. and Ram, P.C. (2003) Physiological and Molecular Basis of Susceptibility and Tolerance of Rice Plants to Complete Submergence. Annals of Botany, 91, 227-241. http://dx.doi.org/10.1093/aob/mcf242

[7] Steffens, B., Steffen-Heins, A. and Sauter, M. (2013) Reactive Oxygen Species Mediate Growth and Death in Submerged Plants. Frontiers in Plant Science, 4, 179. http://dx.doi.org/10.3389/fpls.2013.00179

[8] Sharma, P., Jha, A.B., Dubey, R.S. and Pessarakli, M. (2012) Reactive Oxygen Species, Oxidative Damage, and Antioxidative Defense Mechanism in Plants under Stressful Conditions. Journal of Botany, 2012, Article ID: 217037, 26 p. http://dx.doi.org/10.1155/2012/217037

[9] Jackson, M.B., Ishizawa, K. and Ito, O. (2009) Evolution and Mechanisms of Plant Tolerance to Flooding Stress. Annals of Botany, 103, 137-142. http://dx.doi.org/10.1093/aob/mcn242

[10] Panda, D. and Sarkar, R.K. (2011) Non-Structural Carbohydrate Metabolism Associated with Submergence Tolerance in Rice. Genetics and Plant Physiology, 1, 155-162.

[11] Dhindsa, R.S., Plumb-Dhindsa, P. and Thorpe, T.A. (1981) Leaf Senescence: Correlated with Increased Levels of Membrane Permeability and Lipid Peroxidation, and Decreased Levels of Superoxide Dismutase and Catalase. Journal of Experimental Botany, 32, 93-101. http://dx.doi.org/10.1093/jxb/32.1.93

[12] Verbeke, P., Siboska, G.E., Clark, B.F.C. and Rattan, S.I.S. (2000) Kinetin Inhibits Protein Oxidation and Glycoxidation in Vitro. Biochemical and Biophysical Research Communications, 276, 1265-1270. http://dx.doi.org/10.1006/bbrc.2000.3616

[13] Bradford, M.M. (1976) Rapid and Sensitive Method for Quantitation of Micro Gram Quantities of Protein Utilizing the Principle of Protein-Binding Dye. Analytical Biochemistry, 72, 248-254. http://dx.doi.org/10.1016/0003-2697(76)90527-3

[14] Mohsen, S. and Ammar, A.S.M. (2009) Total Phenolic Contents and Antioxidant Activity in Maize Tassel Extract. Food Chemistry, 112, 595-598. http://dx.doi.org/10.1016/j.foodchem.2008.06.014

[15] Mohamed, A.A. and Aly, A.A. (2008) Alteration of Some Secondary Metabolites and Enzymes Activity by Using Exogenous Antioxidant Compound in Onion Plants Grown under Seawater Salt Stress. American Eurasian Journal of Science Research, 3, 139-146.

[16] Hu, Y., Ge, Y., Zang, C., Zu, T. and Cheng, W. (2009) Cadmium Toxicity and Translocation in Rice Seedlings Are Reduced by Hydrogen Peroxide Treatments. Plant Growth Regulation, 5, 51-61. http://dx.doi.org/10.1007/s10725-009-9387-7

[17] Ghosh, N., Adak, M.K., Ghosh, P.D., Gupta, S., Sengupta, D.N. and Mandal, C. (2011) Differential Responses of Two Rice Varieties to Salt Stress. Plant Biotechnology Reports, 5, 89-103. http://dx.doi.org/10.1007/s11816-010-0163-y

[18] Ammar, W.B., Nouairi, I., Zarrouk, M., Ghorbel, M.H. and Jemal, F. (2008) Antioxidative Response to Cadmium in Roots and Leaves of Tomato Plants. Biologia Plantarum, 5, 727-731. http://dx.doi.org/10.1007/s10535-008-0140-2 
[19] Mandal, C., Ghosh, N., Dey, N. and Adak, M.K. (2014) Effects of Putrescine on Oxidative Stress Induced by Hydrogen Peroxide in Salvinia natans L. Journal of Plant Interactions, 1, 550-558. http://dx.doi.org/10.1080/17429145.2013.871076

[20] Ghosh, N., Das, S.P., Mandal, C., Gupta, S., Das, K., Dey, N. and Adak, M.K. (2012) Variations of Antioxidative Responses in Two Rice Cultivars with Polyamine Treatment under Salinity Stress. Physiology and Molecular Biology of Plants, 4, 301-313. http://dx.doi.org/10.1007/s12298-012-0124-8

[21] Mandal, C., Ghosh, N., Maiti, S., Das, K., Gupta, S., Dey, N. and Adak, M.K. (2013) Antioxidative Responses of Salvinia (Salvinia natans Linn.) to Aluminium Stress and Its Modulation by Polyamine. Physiology and Molecular Biology of Plants, 1, 91-103. http://dx.doi.org/10.1007/s12298-012-0144-4

[22] Blokhina, O., Virolainen, E. and Fagerstedt, K.V. (2003) Antioxidants Oxidative Damage and Oxygen Deprivation Stress: A Review. Annals of Botany, 91, 179-194. http://dx.doi.org/10.1093/aob/mcf118

[23] Upadhyay, R.K., Panda, S.K. and Dutta, B.K. (2009) Growth, Chlorophyll and Electric Conductivity Responses of Rice Cultivars to Different Levels of Submergence and Post-Submergence Stress. Journal of Phytology, 1, 425-432.

[24] Fukao, T. and Bailey-Serres, J. (2008) Ethylene-A Key Regulator of Submergence Responses in Rice. Plant Science, 175, 43-51. http://dx.doi.org/10.1016/j.plantsci.2007.12.002

[25] Nishiuchi, S., Yamauchi, T., Takahashi, H., Kotula, L. and Nakazono, M. (2012) Mechanisms for Coping with Submergence and Waterlogging in Rice. Rice, 5, 2. http://dx.doi.org/10.1186/1939-8433-5-2

[26] Sagi, M. and Fluhr, R. (2006) Production of Reactive Oxygen Species by Plant NADPH Oxidases. Plant Physiology, 141, 336-340. http://dx.doi.org/10.1104/pp.106.078089

[27] Sarkar, R.K., Das, S. and Ravi, I. (2001) Changes in Certain Antioxidative Enzymes and Growth Parameters as a Result of Complete Submergence and Subsequent Re-Aeration of Rice Cultivars Differing in Submergence Tolerance. Journal of Agronomy \& Crop Science, 187, 69-74. http://dx.doi.org/10.1046/j.1439-037X.2001.00510.X

[28] Ramakrishna, A. and Ravishankar, G.A. (2011) Influence of Abiotic Stress Signals on Secondary Metabolites in Plants. Plant Signalling \& Behaviour, 6, 1720-1731. http://dx.doi.org/10.4161/psb.6.11.17613

[29] Xu, K., Xu, X., Fukao, T., Canlas, P., Maghirang-Rodriguez, R., Heuer, S., Ismail, A.M., Bailey-Serres, J., Ronald, P.C. and Mackill, D.J. (2006) Sub1A Is an Ethylene-Responsive-Factor-Like Gene That Confers Submergence Tolerance to Rice. Nature, 442, 705-708. http://dx.doi.org/10.1038/nature04920

[30] Pyngrope, S., Bhoomika, K. and Dubey, R.S. (2012) Oxidative Stress, Protein Carbonylation, Proteolysis and Antioxidative Defense System as a Model for Depicting Water Deficit Tolerance in Indica Rice Seedlings. Plant Growth Regulation, 2, 149-165.

[31] Mika, A., Boenisch, M.J., Hopff, D. and Lüthje, S. (2010) Membrane-Bound Guaiacol Peroxidases from Maize (Zea mays L.) Roots Are Regulated by Methyljasmonate, Salicylicacid, and Pathogen Elicitors. Journal of Experimental Botany, 61, 831-841. http://dx.doi.org/10.1093/jxb/erp353 
Scientific Research Publishing (SCIRP) is one of the largest Open Access journal publishers. It is currently publishing more than 200 open access, online, peer-reviewed journals covering a wide range of academic disciplines. SCIRP serves the worldwide academic communities and contributes to the progress and application of science with its publication.

Other selected journals from SCIRP are listed as below. Submit your manuscript to us via either submit@scirp.org or Online Submission Portal.
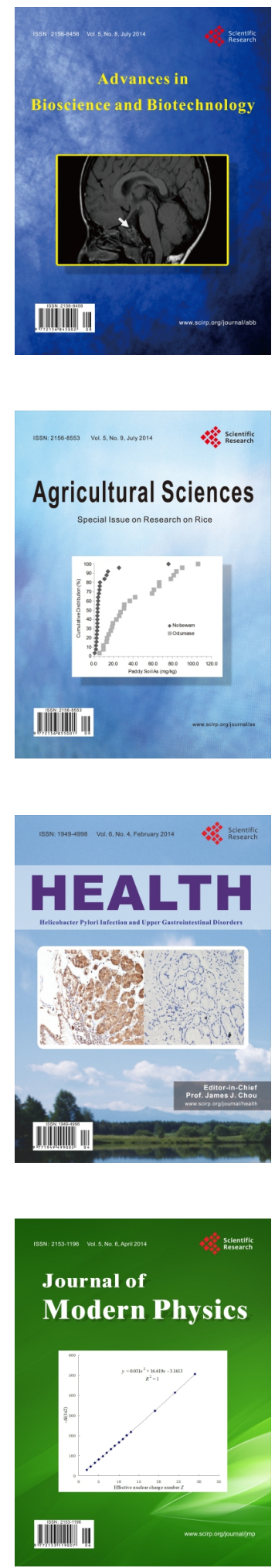
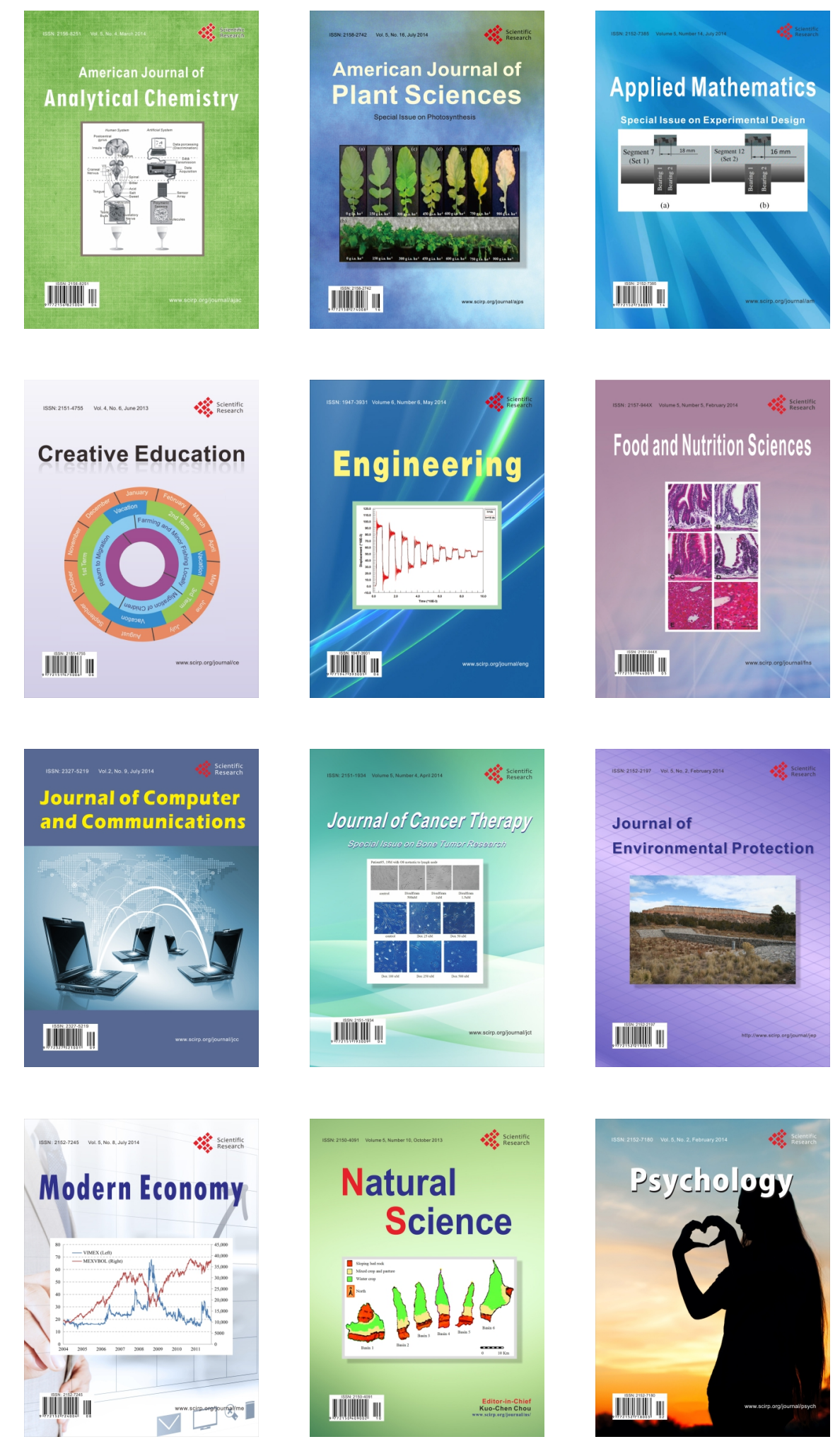